\title{
RESUMO
}

\section{A ESCOLA COMO PROTAGONISTA NO ENFRENTAMENTO AO CYBERBULLYING INFANTOJUVENIL: PERSPECTIVAS EDESAFIOS}

\section{SCHOOL AS A PROTAGONIST IN THE FACE OF JUVENILE CYBERBULLYING: PERSPECTIVES AND CHALLENGES}

\section{LA ESCUELA COMO PROTAGONISTA ANTE EL CIBERACOSO INFANTOJUVENLL: PERSPECTIVAS Y DESAFÍOS}

0 presente artigo objetiva analisar o papel da escola na prevenção ao cyberbullying através da atuação dos atores sociais envolvidos bem como a partir da verificação de ações que materializem as disposições da Lei 13.185/15, que instituiu o Programa de Combate à Intimidação Sistemática. Seu viés preventivo anuncia a opção por medidas restaurativas no trato dos conflitos. A metodologia utilizada fora qualitativa e quantitativa. Concluiu-se que a articulação da Rede de Proteção na busca pelo combate ao cyberbullying é fator preponderante para a proteção da infância brasileira.

\section{PALAVRAS-CHAVE}

Cyberbullying. Escola. Sistema de Garantia dos Direitos Infantojuvenis.
Émile Dantas de Carvalho Cartaxo ${ }^{1}$ Tanise Zago Thomasi ${ }^{2}$ Diogo de Calasans Melo Andrade ${ }^{3}$ 


\section{ABSTRACT}

This article aims to analyze the role of the school in preventing cyberbullying through the actions of the social actors involved, as well as from the verification of actions that materialize the provisions of Law 13.185/15, which instituted the Program to Combat Systematic Intimidation. Its preventive bias announces the option for restorative measures to deal with conflicts. The methodology used was qualitative and quantitative. It was concluded that the articulation of the Protection Network in the search to combat cyberbullying is a major factor for the protection of Brazilian childhood.

\section{KEYWORDS}

Cyberbullying. School. Child Rights Guarantee System.

\section{RESUMEN}

Este artículo tiene como objetivo analizar el papel de las escuelas en la prevención del ciberacoso a través del rol de los actores sociales involucrados, así como a través de la verificación de acciones que materializan lo dispuesto en la Ley 13.185/15, que instituyó el Programa de Combate a la Intimidación Sistemática. Su sesgo preventivo anuncia la opción de medidas reparadoras en el tratamiento de conflictos. La metodología utilizada fue cualitativa y cuantitativa. Se concluyó que la articulación de la Red de Protección en la búsqueda del combate al ciberacoso es un factor preponderante para la protección de la niñez brasileña.

\section{PALABRAS CLAVE}

Ciberacoso. Colegio. Sistema de Garantía de los Derechos de la Niñez y la Adolescencia. 


\section{INTRODUÇ̄̃O}

Expressão usual para referir-se às crianças, adolescentes e jovens no tempo presente "nativos digitais" reflete as diversas e irreversíveis transformações ocorridas no seio social. 0 uso de novas tecnologias impõe repensar estruturas, que vão desde a relação com o conhecimento até relações interpessoais. Aliado às possibilidades reais e recorrentes do uso inadequado da internet, ao recente movimento do ordenamento jurídico para atentar-se à regulamentação de tais questões, bem como às estatísticas levantadas até o momento no Brasil, o tema é de suma relevância para fundamentar discussões futuras, debates construtivos e colaborar no processo de cidadania ativa e participativa.

Nesse contexto, é preciso compreender o papel central da escola como lócus privilegiado para o desenvolvimento dessa infância, adolescência e juventude que assim vivencia intensamente esse processo de revolução digital, razão pela qual se constitui o presente problema da pesquisa: como a escola, integrante da rede de proteção infantojuvenil, tem atuado diante do fenômeno do cyberbullying?

0 presente trabalho tem por objetivo geral compreender o papel da escola como protagonista na prevenção ao cyberbullying por meio da atuação em Rede e implantação de programas que materializem as disposições da Lei 13.185/2015.

\section{MÉTODO}

Em termos metodológicos, trata-se de pesquisa qualitativa e quantitativa, uma vez que faz a análise de literatura, mas também de estatísticas, utilizando-se metodologicamente, quanto aos procedimentos, da técnica bibliográfica, a partir da revisão de literatura realizada nos principais pontos a serem abordados: escola, rede de proteção, bullying e cyberbullying; e ainda técnica documental, consistente na análise de dados, relatórios, matérias, estatísticas governamentais e não governamentais sobre o assunto.

Para alcançar os objetivos, o trabalho encontra-se dividido em 2 partes. Inicialmente, contextualiza-se o cenário de construção de tutela integral das crianças e adolescentes, destacando-se o papel do Sistema de Garantia dos Direitos da Criança e do Adolescente, que a título simplificativo, será denominado de rede de proteção, com ênfase na escola, conceituando, também, o fenômeno em estudo do cyberbullying. Em seguida, avalia-se o cenário da violência infantojuvenil a partir do cyberbullying por estatísticas levantadas em sites governamentais, não governamentais e relatórios, bem como o papel da escola nesse contexto, destacando experiências paradigmas exitosas nesse processo de promoção e efetivação de direitos humanos infantojuvenis, com ênfase na importância da educação nesse cenário.

Constatou-se com o presente estudo que o Brasil, por meio de ações e programas tem convergido para o rompimento do paradigma do silêncio e da normalidade quanto ao cyberbullying. As inovações legislativas são um reflexo desse olhar de atenção, e que, em razão de seu recente nascedouro, carecem de mais experimentações, debates e reflexões, para que, em harmonia e consonância com a realidade possam então produzir transformação. 
Ademais, a intersetorialidade dos atores no Sistema de Garantia dos Direitos Infantojuvenis e a integração efetiva é um fator primordial no combate ao cyberbullying que precisa ser fortalecido, juntamente com a segurança e robustez da geração de dados para a formação de políticas públicas de fato.

\section{DIREITOS HUMANOS INFANTOJUVENIS: A CONSTRUCÇÃO INTERNACIONAL E NACIONAL DE UM CENÁRIO DE PROTEÇÃO INTEGRAL}

Falar em direitos humanos de crianças e adolescentes é falar em um árduo processo de lutas, discussões e participação popular. A contextualização do cenário internacional e nacional que subsidiaram a consolidação do paradigma da proteção integral constitui elemento imprescindível por ser, inclusive, constituidor do que a doutrina denomina atualmente de Novo Direito da Criança e do Adolescente.

As mobilizações, envolvendo as organizações populares nacionais e de setores infantojuvenis, aliadas ao cenário de pressão de organismos internacionais, como a Fundo das Nações Unidas para a Infância (UNICEF), foram primordiais para que o legislador constituinte se tornasse sensível às demandas pela tutela jurídica já reconhecida por diversos instrumentos internacionais, a exemplo da Declaração de Genebra de 1924; a Declaração Universal dos Direitos Humanos das Nações Unidas de 1948; a Convenção Americana Sobre os Direitos Humanos de 1969 e Regras Mínimas de Beijing (Res. 40/33 da Assembleia-Geral, de 29 de novembro de 1985) (AMIN, 2014).

Na seara internacional, o ápice da garantia aos direitos infantojuvenis se deu com a Convenção sobre os Direitos da Criança de 1989, que, na qualidade de norma jus cogens e, inclusive, com maior número de ratificações no mundo (com única exceção dos Estados Unidos), consubstancia a doutrina da Proteção Integral, à medida que põe fim ao pensamento da criança e do adolescente como objeto de direito e inaugura um sistema de proteção jurídica de sujeitos de direitos humanos.

A Convenção Internacional surge justamente como um dispositivo central da nova doutrina da proteção integral, inaugurando um novo paradigma que possibilita repensar, de forma profunda, o sentido das legislações voltadas para a proteção da infância, transformando-as em instrumentos eficazes de defesa e promoção dos direitos humanos de todas as crianças e adolescentes (MÉNDEZ, 1998).

No âmbito doméstico, influenciado pelo período de redemocratização e da promulgação da Constituição Federal de 1988, o Estatuto da Criança e do Adolescente (ECA) é fruto desse novo olhar e dessa nova perspectiva de proteção integral.

O ECA resultou essencialmente da articulação dos movimentos sociais, dos agentes jurídicos e das políticas públicas. Ao movimento social incumbiu a tarefa de reivindicar e pressionar, e aos agentes jurídicos a tarefa de traduzir em termos técnicos os anseios da sociedade civil desejosa de mudança no âmbito jurídico e institucional das décadas anteriores.

Assim, inserido pelo ambiente propício de retomada democrática pós-ditadura militar e promulgação de uma nova ordem constitucional, coube ao poder público, por meio do Poder Legislativo, efetivar os anseios sociais e a determinação constitucional no plano normativo interno (AMIN, 2014). 
Inaugura-se com o ECA um modelo jurídico de proteção integral das crianças e adolescentes, envolvendo nessa proteção não somente o Estado, mas a família e a sociedade cuja tutela não se restringe aos jovens em situação de vulnerabilidade socioeconômica, abrangendo, "todas as crianças e adolescentes, pobres ou ricos, lesados em seus direitos fundamentais de pessoas em desenvolvimento" (AMIN, 2014, p. 51).

Apesar do vasto aparato inovador normativo, a realidade mundial e brasileira ainda destoa destas conquistas, por isso a problematização da pesquisa se constitui a partir de como a educação e a escola podem ser instrumentos de materialização de direitos humanos para crianças e adolescentes, uma análise voltada ao fenômeno do cyberbullying.

Com efeito, a compreensão da Educação, com ênfase no papel da escola, da Rede de Proteção e Garantia de Direitos e o fenômeno do cyberbullying como objeto específico nesta pesquisa se mostram fundamentais nesse cenário de busca de alternativas para redimensionar o atual contexto de violação de direitos infantojuvenis.

A educação está prevista na Carta Magna e no Estatuto da Criança e do Adolescente como direito, delineado a partir do caput do artigo 53 do ECA, estabelecendo-se que a criança e o adolescente têm direito à educação, visando-se, além do pleno desenvolvimento de sua pessoa, o preparo para o exercício da cidadania e qualificação para o trabalho. Dessa forma, percebe-se que o ECA, ao tratar do direito à educação, intencionalmente "hierarquiza os objetivos da ação educativa, colocando em primeiro lugar o pleno desenvolvimento do educando como pessoa, em segundo lugar o preparo para o exercício da cidadania e em terceiro lugar a qualificação para o trabalho" (COSTA, 2013, p. 264).

A Convenção sobre os Direitos da Criança de 1989 também é clara ao reconhecer e priorizar a educação, trazendo inclusive no artigo 28.3 a promoção à cooperação internacional quando o assunto é educação, justificando, assim, a interface com o tema educação, violência, rede de proteção e organismos internacionais.

A Rede de Proteção e Garantias é denominada pela Resolução no 113 do Conselho Nacional dos Direitos da Criança e do Adolescente (CONANDA) de Sistema de Garantia dos Direitos da Criança e do Adolescente (SGDCA). A referida resolução, em seu artigo $1^{\circ}$ define que "O Sistema de Garantias dos Direitos da Criança e do Adolescente constitui-se na articulação e integração das instâncias públicas governamentais e da sociedade civil". A mencionada articulação envolve, por exemplo, a área de saúde, educação, assistência social, trabalho, segurança pública, planejamento orçamentário e promoção da igualdade e valorização da diversidade.

Dessa maneira, articulação e integração constituem os eixos centrais da definição e da estruturação Sistema de Garantia dos Direitos da Criança e do Adolescente. Ainda, é possível inferir que a criação de um sistema visa romper com o dualismo Sociedade Civil versus Estado, uma vez que todos são responsáveis e devem atuar em prol do interesse da criança e do adolescente.

0 reconhecimento de cada ator social e de suas funções nesse cenário é um dos passos iniciais para o amadurecimento social, bem como da noção de que o problema da violência infantojuvenil interessa a toda coletividade. Assim, é de suma importância a compreensão por parte dos atores sociais a respeito do Sistema, tendo em vista que toda promoção, proteção e controle dos direitos infantojuvenis assentam-se sob o bojo desse sistema. 
Em linhas gerais, o SGDCA surge com a finalidade de aproximar o serdo dever ser, a realidade que está posta em termos de Brasil com a realidade da lei, visando "diminuir a distância entre a regulamentação que temos, considerada adequada e exemplar, e a realidade de violação de direitos vivida pela maioria das crianças e adolescentes brasileiros” (REZENDE, 2013, p. 7-8).

Isso implica agir para que a legislação seja cumprida, que os esforços sejam alocados em transformar a realidade para aquela desenhada pela lei; não o inverso. É necessário, dessa forma, avançar para mudanças de contextos de ausência de garantias e violações dos direitos infantojuvenis e não de avanços adstritos somente ao campo normativo.

A articulação e a integração de agentes estatais e não estatais, nessa perspectiva, é relevante não somente por possibilitar a abertura de caminhos concretos de mudança do atual cenário vigente, mas para a imbuir em todos, inclusive, na sociedade civil, que a proteção da infância e da adolescência implica, de fato, responsabilidades para com os outros.

\section{DISCUTINDO VIOLEANCIA INFANTOJUVENLL, CYBERBULLYING, EDUCAÇ̃̃O E PROTAGONISMO DA ESCOLA: CONTEXTOS E PERSPECTIVAS}

Combater todas as formas de violência infantojuvenil não constitui somente uma necessidade de ordem prática, mas, em verdade, uma forma de garantir uma existência digna à população infantojuvenil vulnerável.

No mundo, "a estimativa do UNICEF é de que, se as tendências atuais permanecerem, quase dois milhões de crianças e adolescentes serão mortos por um ato de violência até 2030". Atualmente, a Organização Mundial da Saúde (OMS) aponta que a cada 7 minutos, em algum lugar do mundo, crianças ou adolescentes entre 10 e 19 anos são mortos por consequência da violência (UNICEF, 2017, p. 11; 49).

Essa violência assume diversas formas, incluindo a agressão física, abuso ou tratamento negligente, maus tratos ou exploração, abuso sexual, também o bullying ou cyberbullying.

Ainda de acordo com a Unicef (2017), a negligência ou abandono, o trabalho infantil e a violência financeira também constituem formas de manifestação direta da violência. Entender a prioridade que deve ser dada a temática passa pela reflexão de alguns dados estatísticos, que evidenciam o contraste entre o ser e o dever ser.

O Relatório da Unicef (2017) traz uma série de estatísticas a respeito da violência infantojuvenil. Quando se fala em disciplina violenta/castigos físicos, tem-se que

Aproximadamente 300 milhões de crianças de 2 a 4 anos em todo o mundo - três em cada quatro - sofrem, regularmente, disciplina violenta por parte de seus cuidadores e $250 \mathrm{mi}$ lhões - cerca de seis em cada dez - são punidas com castigos físicos. (UNICEF, 2017, p. 7).

Nessa seara, a violência se apresenta de forma muito precoce. "Com base em dados de 30 países, seis em cada dez crianças entre 12 e 23 meses de idade estão submetidas a ela. Entre crianças muito pequenas, quase metade sofre castigo físico e uma proporção similar está exposta ao abuso verbal” (UNICEF, 2017, p. 7). 
É importante conceituar, atendo-se ao objeto específico de estudo da pesquisa, o fenômeno do cyberbullying a partir de um olhar multidimensional. De início a Lei 13.185, de 6 de novembro de 2015, que institui o Programa de Combate à Intimidação Sistemática (Bullying), traz em seu primeiro artigo:

No contexto e para os fins desta Lei, considera-se intimidação sistemática (bullying) todo ato de violência física ou psicológica, intencional e repetitivo que ocorre sem motivação evidente, praticado por indivíduo ou grupo, contra uma ou mais pessoas, com o objetivo de intimidá-la ou agredi-la, causando dor e angústia à vítima, em uma relação de desequilíbrio de poder entre as partes envolvidas (BRASIL, 2015, on-line).

Já a intimidação sistemática na rede mundial de computadores (cyberbullying), conforme art. $2^{\circ}$, parágrafo único da Lei 13.185/2015 ocorre "quando se usarem os instrumentos que lhe são próprios para depreciar, incitar a violência, adulterar fotos e dados pessoais com o intuito de criar meios de constrangimento psicossocial”, classificando-se nos termos da lei como intimação sistemática virtual, uma vez que seu locus é a rede e se caracteriza pela ocorrência de depreciação, envio de mensagens intrusivas da intimidade, envio ou adulteração de fotos e dados pessoais que resultem em sofrimento ou com o intuito de criar meios de constrangimento psicológico e social.

Partindo para o viés doutrinário, entende Borelli e Zamperlin (2017, p. 331):

O cyberbullying pode ser compreendido como o bullying praticado em ambiente virtual, on-line. Ele não tem fronteiras, não tem limites, quaisquer que sejam, pois, acreditando que estão sob o manto do anonimato, inicialmente propiciado pela internet (mas que pode ser afastado com medidas jurídicas), os agressores se multiplicam e não têm identidade. A vítima não consegue dimensionar o dano, e os agressores estão em todos os locais, a todo tempo.

Assim, cada vez mais se faz nítida a relação entre os avanços tecnológicos e as novas formas de delinquência informática, necessitando, assim, do olhar dos operadores do direito para essa nova dimensão que se estabelece para o ordenamento jurídico.

O Conselho Nacional de Justiça (CNJ, 2016, p. 7) define o bullying como "em última instância, significa dizer que, de forma "natural”, os mais fortes utilizam os mais frágeis como meros objetos de diversão, prazer e poder, com o intuito de maltratar, intimidar, humilhar e amedrontar suas vítimas”.

Logo, é grande a importância de se refletir relações entre as estatísticas, o ambiente escolar e as potencialidades para o fortalecimento da proteção infantojuvenil, isso porque quando se analisa essa violência e a sua relação com a Educação encontra-se estreita relação dessas vítimas com o atraso escolar ou até mesmo estarem fora dessa realidade de estudo.

Privações múltiplas vivem crianças e adolescentes, que além da educação possuem outros direitos básicos negados como moradia, saneamento básico, saúde entre outros, com uma representatividade que em números é estrondosa, em torno de 27 milhões de crianças e adolescentes brasileiros, praticamente metade $(49,7 \%)$ da população brasileira até 17 anos, conforme aponta o Relatório da Unicef Brasil (2018, p. 6) intitulado "Pobreza na Infância e na Adolescência”. 
“No Brasil, mais de 7 milhões de estudantes da educação básica estão em situação de distorção idade-série - ou seja: têm dois ou mais anos de atraso escolar", dados apresentados no Relatório intitulado Panorama da distorção idade-série no Brasil produzido pela Unicef Brasil (2018, p. 3). Assim, a falta do acesso e permanência na escola interfere diretamente no grau de vulnerabilidade de milhões de crianças e adolescentes, o que fortalece a relação presente entre educação e direitos e falta de educação e violência.

Motivo pelo qual se defende a escola com papel de extrema relevância no contexto em tela, uma vez que, do ponto de vista jurídico, atua como garantidora da integridade infantojuvenil sob sua responsabilidade, nos termos do artigo 245 do ECA, sendo o papel do professor/educador relevante nessa relação de ensino e formação, ainda do ponto de vista social e pedagógico, tendo em vista que "a escola projeta a vida social - que é dinâmica - marcada pela pluralidade de sujeitos" (SILVA; BEZERRA; SILVA, 2016, p. 150).

Ainda sobre o papel da escola, orienta o CNJ (2016, p. 12):

A escola é corresponsável nos casos de bullying, pois é lá onde os comportamentos agressivos e transgressores se evidenciam ou se agravam na maioria das vezes. A direção da escola (como autoridade máxima da instituição) deve acionar os pais, os Conselhos Tutelares, os órgãos de proteção à criança e ao adolescente etc. Caso não o faça, poderá ser responsabilizada por omissão. Em situações que envolvam atos infracionais (ou ilícitos), a escola também tem o dever de fazer a ocorrência policial. Dessa forma, os fatos podem ser devidamente apurados pelas autoridades competentes e os culpados responsabilizados. Tais procedimentos evitam a impunidade e inibem o crescimento da violência e da criminalidade infantojuvenil.

Por meio de uma educação integrada e articulada, abrem-se espaços institucionais para concretizar não somente o acesso universal à educação, mas, sobretudo, para o enfrentamento da exclusão social e da erradicação da pobreza, garantindo-se a cidadania (CUSTÓDIO; MOREIRA, 2015).

Educar para transformar. Eis o desafio para os atores sociais na busca por transformações e resultados concretos de enfrentamento ao cyberbullying, mas também a toda forma de violência infantojuvenil vigente no atual cenário.

\subsection{CENÁRIO DO BULLYINGE CYBERBULLYINGEM ESTATISTICAS E EXPERIÊNCIAS: RESULTADOS E ESPAÇOS PARA REFLEXÃO}

A Lei 13.185/2015 que institui o Programa de Combate à Intimidação Sistemática (Bullying) e teve como marco inicial de sua vigência em fevereiro de 2016 optou pelo viés restaurativo no combate ao bullying em todas suas formas. Breve análise por ela fornece elementos suficientes para aferir sua escolha por medidas preventivas e restaurativas, em harmonia com as normas internacionais, a Constituição Federal, O ECA e demais normas, a exemplo do artigo $4^{\circ}$, incisos V, VIII e IX e artigo $5^{\circ}$ da lei em estudo. 
Todavia, representa significativo erro pensar que a prevenção não gera responsabilização ou outras medidas, uma vez que o ECA é claro ao tratar:

Art. 70. É dever de todos prevenir a ocorrência de ameaça ou violação dos direitos da criança e do adolescente.

Art. 70-A. A União, os Estados, o Distrito Federal e os Municípios deverão atuar de forma articulada na elaboração de políticas públicas e na execução de ações destinadas a coibir o uso de castigo físico ou de tratamento cruel ou degradante e difundir formas não violentas de educação de crianças e de adolescentes, tendo como principais ações:

III - a formação continuada e a capacitação dos profissionais de saúde, educação e assistência social e dos demais agentes que atuam na promoção, proteção e defesa dos direitos da criança e do adolescente para o desenvolvimento das competências necessárias à prevenção, à identificação de evidências, ao diagnóstico e ao enfrentamento de todas as formas de violência contra a criança e o adolescente; (BRASIL, 1990, on-line).

Em que pese a Lei 13.185/2015 possuir mais de cinco anos desde o início de sua vigência, o acervo estatístico por meio de pesquisas e dados robustos ainda é limitado. Esse ponto é crítico, uma vez que sem uma análise comprometida da realidade, por meio de dados qualitativos e quantitativos, a margem de experiências não exitosas aumenta no tocante às ações e políticas em torno do objeto.

A nível nacional, realizando as buscas dos dados, o último levantamento feito sobre o tema (bullying dentro do ambiente escolar) "data, justamente, de 2015. Na época, a pesquisa do IBGE sobre saúde escolar constatou que 7,4\% dos estudantes - ou mais de 195 mil alunos - sofriam bullying todos os dias" (ARGENTA; MARQUES, 2018).

A nível global, a Unicef divulgou no segundo semestre de 2019, recente pesquisa feita com aproximadamente 170 mil participantes entre 13 e 24 anos, de nacionalidades diversas, por meio da ferramenta de engajamento de jovens U-Report. A pesquisa, feita através de SMS e mensagens instantâneas, se relacionou em torno do conhecimento a respeito das "experiências de bullying e de violência on-line, onde estes atos acontecem com mais frequência e quem seriam os responsáveis por acabar com as práticas" (ONU NEWS, 2019).

Os resultados reforçam a atenção que merece o tema e o caminho que ainda há a ser percorrido: "cerca de três quartos dos jovens disseram que plataformas incluindo Facebook, Instagram, Snapchat e Twitter são as mais comuns para o bullying online" (ONU NEWS, 2019, on-line). Ainda, "um em cada três jovens em 30 países disse ter sido vítima de bullying online, com um em cada cinco relatando ter saído da escola devido a cyberbullying e violência" (ABRACE..., 2019b). "Cerca de 32\% dos entrevistados disseram acreditar que os governos devem ser os responsáveis pelo fim do cyberbullying, 31\% apontaram que são os jovens enquanto $29 \%$ mencionaram as empresas de internet” (ONU NEWS, 2019, on-line).

Em paralelo e de modo a convergir com o presente artigo, por meio da pesquisa Professores e Líderes Escolares como Eternos Aprendizes (Talis, sigla em inglês), divulgada também no segundo semestre de 2019 pela Organização para a Cooperação e Desenvolvimento Econômico (OCDE), por levantamento com 2,4 mil educadores brasileiros, aponta índices elevados de tempo desperdiçado com tarefas que não são de aprendizado e de casos de intimidação, afetando alunos e professores, o 
que representa uma média de $67 \%$ do tempo com o processo de aprendizado, inferior à média OCDE, correspondente a $78 \%$, para um universo de 250 mil professores e líderes escolares de 48 países ou regiões entrevistados.

Somente os professores da África do Sul e da Arábia Saudita gastam mais tempo com tarefas não relacionadas ao aprendizado do que o Brasil (ABRACE ..., 2019a). Em outras palavras, há um grande quantitativo de horas perdidas com atividades administrativas ou disciplinares.

Quanto aos índices de bullying apontados na pesquisa, tem-se que $28 \%$ dos diretores escolares brasileiros relataram ter testemunhado situações de intimidação ou bullying entre alunos, o dobro da média da OCDE. Ainda, semanalmente, $10 \%$ das escolas brasileiras pesquisadas registram episódios de intimidação ou abuso verbal contra educadores, todavia a média internacional corresponde a 3\% (ABRACE..., 2019a), estatísticas que revelam o quanto o tema precisa ser levado a sério pela sociedade.

Por isso, também a importância de destacar iniciativas que tem apoiado e se comprometido com a problemática. Globalmente, a campanha \#ENDviolence in Schools, tem como finalidade precípua orientar para a abordagem do fenômeno dentro e ao redor das escolas, buscando a redução da violência infantojuvenil por meio de serviços de prevenção. Na campanha, definiu-se cinco áreas estratégicas de atuação. Dentre as quais, destaca-se a implementação de políticas e leis nas esferas nacionais, regionais e locais, o fortalecimento da prevenção e a resposta a nível escolar, envolvendo funcionários da escola, alunos e comitês de gestão na promoção de ambientes de aprendizagem seguros e sensíveis aos gêneros que promovam a disciplina positiva (UNICEF BRASIL, 2019)

A título exemplificativo, a nível nacional, tem-se o Sistema de Aviso Legal por Violência e Exploração Contra a Criança e o Adolescente (SALVE) desenvolvido pelo Ministério Público Estadual de Sergipe, com ênfase nos educadores e demais profissionais da educação, uma vez que em grande maioria são os primeiros agentes a tomarem conhecimento de risco ou lesão aos direitos infantojuvenis (LEOPOLDO; ALVES, 2016).

Ainda, a Polícia Militar de Sergipe desenvolve o Programa Educacional de Resistência às Drogas e à Violência (PROERD), que tem como metodologia a Teoria Socioemocional, que trabalha os sentimentos e emoções dos alunos, implementado no ano de 2001 e trabalha diretamente de forma preventiva com alunos e alunas nas escolas, tratando inclusive a temática do bullying.

\section{CONCLUSÃO}

O exercício da cidadania pressupõe o reconhecimento do eu e do outro como ser. Os princípios que tutelam o direito infantojuvenil partem também da premissa de sua condição peculiar de seres humanos em desenvolvimento, por isso a ordem jurídica é clara na corresponsabilidade na prestação e garantia de tais direitos. Todos devem garantir o pleno desenvolvimento infantojuvenil, cuja materialização envolve responsabilidades estatais e da própria sociedade civil.

Em que pese a tutela das crianças e adolescentes ocorra de forma satisfatória no âmbito normativo, a realidade mundial e brasileira ainda destoa destas conquistas, razão pela qual se faz necessário 
pensar alternativas viáveis, jurídica e socialmente, para a concretização dos direitos infantojuvenis, o que inclui o crescente interesse pelo estudo de práticas restaurativas até o direito à educação e valorização do ambiente escolar como locus adequado ao desenvolvimento humano.

Nessa relação, as novas tecnologias não podem ser negadas ou tratadas como responsáveis exclusivas do sistema. 0 olhar que emerge é o de entendimento e equilíbrio, uma vez que como parte dessa geração de nativos digitais, podem ser também ferramentas na sociabilidade e formação destes jovens.

Constatou-se que o aprimoramento dos sistemas de informações sobre crianças e adolescentes é um aspecto de extrema relevância no aperfeiçoamento da Rede de Proteção. O fortalecimento e a continuidade do trabalho conjunto das instituições, o aperfeiçoamento da coleta de dados e a articulação e intersetorialidade dos atores no Sistema (SGDCA) são imprescindíveis para gerar e usar evidências.

Gerar esforços para materializar o vasto arcabouço de normas de proteção à infância e à adolescência, por meio de políticas públicas e programas que atendam às necessidades dos municípios e estados, é uma indigência cada vez mais imperiosa e urgente no Brasil, razão pela qual é fundamental a importância e a integração de organismos internacionais nesse cenário de luta e de busca de alternativas factíveis, a exemplo da educação.

Nessa senda, constatou-se que a escola deve se empenhar numa gestão que trace estratégias para romper o ciclo de produção e reprodução da violência em seu ambiente, usando ferramentas como a apropriação do diálogo na rotina dos estudantes, o protagonismo juvenil na identidade e responsabilidade do jovem, a mediação de conflitos entre outras ações.

Por fim, a ressignificação do espaço da escola para enfrentar a cultura da violência e do fracasso escolar constitui-se aspecto fundamental para o alcance de novos e transformadores resultados. Inclusão, proteção e participação devem nortear as ações da escola em direção à proteção infantojuvenil.

\section{REFERÊNCIAS}

\section{ABRACE PROGRAMAS PREVENTIVOS. Escolas no Brasil têm menos tempo para ensino e mais bullying entre alunos do que média internacional, indica pesquisa da OCDE. 27 jun. 2019a.} Disponível em: https://abraceprogramaspreventivos.com.br/escolas-no-brasil-tem-menos-tempopara-ensino-e-mais-bullying-entre-alunos-do-que-media-internacional-indica-pesquisa-da-ocde/. Acesso em: 28 set. 2021a.

ABRACE PROGRAMAS PREVENTIVOS. UNICEF: um terço dos jovens em 30 países relata ser vítima de bullying online. 10 set. 2019b. Disponível em: https://abraceprogramaspreventivos.com.br/unicef-umterco-dos-jovens-em-30-paises-relata-ser-vitima-de-bullying-online. Acesso em: 28 set. 2021b.

AMIN, Andréa Rodrigues. Evolução histórica do direito da criança e do adolescente. In: MACIEL, Kátia Regina Ferreira Lobo Andrade (coord.). Curso de direito da criança e do adolescente: aspectos teóricos e práticos. 7. ed. São Paulo: Saraiva, 2014. 
ARGENTA, Évelyn; MARQUES, Clara. Três anos após lei de combate ao bullying, ainda faltam dados oficiais sobre o tema. 30 ago. 2018. Disponível em: http://cbn.globoradio.globo.com/media/ audio/209394/tres-anos-apos-lei-de-combate-ao-bullying-ainda-fa.htm. Acesso em: 28 set. 2021.

BORRELLI, Alessandra; ZAMPERLIN, Borelli Emelyn. Aplicação da Lei de Cyberbullying. Direito digital, íntegra editorial, p. 301-338, 2017.

BRASIL. Lei n⿳0 13.185, de 6 de novembro de 2015. Institui o Programa de Combate à Intimidação Sistemática (Bullying). Disponível em: http://www.planalto.gov.br/ccivil_03/_ato2015-2018/2015/ lei/l13185.htm . Acesso em: 28 set. 2021.

BRASIL. Resolução n⿳0 113. Conselho Nacional dos Direitos da Criança e do Adolescente - Conanda, de 19 de abril de 2006. Dispõe sobre os parâmetros para a institucionalização e fortalecimento do Sistema de Garantia dos Direitos da Criança e do Adolescente. Secretaria especial dos direitos humanos, 2006. Disponível em: https://www.direitosdacrianca.gov.br/conanda/resolucoes/113resolucao-113-de-19-de-abril-de-2006/view . Acesso em: 28 set. 2021.

BRASIL. Lei no 8.069, de 13 de julho de 1990. Dispõe sobre o Estatuto da Criança e do Adolescente e dá outras providências. Disponível em: http://www.planalto.gov.br/ccivil_03/leis//8069.htm . Acesso em: 28 set. 2021.

CNJ - Conselho Nacional de Justiça. Bullying - Cartilha 2016 Projeto Justiça nas Escolas. Texto: Dra. Ana Beatriz Barbosa Silva (Médica psiquiatra, diretora técnica da Medicina do Comportamento SP e RJ, escritora e autora do livro “BULLYING: Mentes Perigosas nas Escolas”). Disponível em: https://www.cnj.jus.br/wp-content/uploads/conteudo/arquivo/2016/11/195bb8727040c594311b9 611ce923f96.pdf. Acesso em: 28 set. 2021.

COSTA, Antônio Carlos Gomes da. Do direito à educação, à cultura, ao esporte e ao lazer- Cap. IV. In: CURY, Munir (coord.). Estatuto da criança e do adolescente comentado: comentários jurídicos e sociais. 12. ed. São Paulo: Malheiros, 2013.

CUSTÓDIO, André Viana; MOREIRA, Rafael Bueno da Rosa. A garantia do direito à educação de crianças e adolescentes no contexto das políticas públicas brasileiras. Revista Brasileira de Políticas Públicas, Brasília, v.5, n. 1, p. 223-245, 2015.

LEOPOLDO, Denise Leal Fontes Albano; ALVES, Robson Cosme de Jesus. Atores, papéis e atribuições na rede de proteção integral e no sistema de garantia de direitos da criança e do(a) adolescente. In: LEOPOLDO, Denise Leal Fontes Albano Leopoldo (org.). Curso de especialização em direitos infanto-juvenis: escola que protege, 2016. Realização: Universidade Federal de Sergipe. São Cristóvão: Cesad, 2016. 
MÉNDEZ, Emílio García. Infância e cidadania na américa latina. São Paulo: Hucitec Instituto Ayrton Senna, 1998.

ONU NEWS. Organização das Nações Unidas. Brasil entre 30 países onde um terço de jovens já sofreu bullying online. Disponível em: https://news.un.org/pt/story/2019/09/1685602 . Publicado 04 set. 2019. Acesso em: 28 set. 2021.

REZENDE, Propercio Antônio de. Considerações sobre o sistema de garantia dos direitos da criança e do adolescente - SGDCA. In: A Escola no combate ao trabalho infantil, 2013. Fundação Instituto de Administração - FIA, Ministério Público do Trabalho, Rede Pró menino, 2013.

SILVA, Priscila Soares; BEZERRA, Daniela Moura; SILVA, Williams Souza. ECA no ambiente escolar. In: Curso de especialização em direitos infanto-juvenis: escola que protege, 2016. Denise Leal Fontes Albano Leopoldo (org.). Realização: Universidade Federal de Sergipe. São Cristóvão: Cesad, 2016.

UNICEF. A Familiar Face: violence in the lives of children and adolescents, 2017. Disponível em: https://data.unicef.org/resources/a-familiar-face/. Acesso em: 28 set. 2021.

UNICEF BRASIL. Relatório A Educação que protege contra violência: dados, análises e recomendações de como o Brasil pode avançar na garantia do direito à educação como estratégia de proteção à vida e de prevenção de mais violências, 2019. Disponível em: https://www.unicef.org/ brazil/relatorios/educacao-que-protege-contra-violencia . Acesso em: 28 set. 2021.

UNICEF BRASIL. Relatório Panorama da distorção idade-série no Brasil. 2018. Disponível em: https://www.unicef.org/brazil/relatorios/panorama-da-distorcao-idade-serie-no-brasil . Acesso em: 28 set. 2021.

UNICEF BRASIL. Relatório Pobreza na infância e na adolescência. 2018. Disponível em: https:// www.unicef.org/brazil/relatorios/pobreza-na-infancia-e-na-adolescencia. Acesso em: 28 set. 2021. 
1 Graduada em Direito pela Universidade Tiradentes (2014). Pós-graduada em Gestão e Modernização Institucional da Segurança Pública pela Universidade Federal de Sergipe (2018). Mestranda em Direitos Humanos pela Universidade Tiradentes. Assessora Técnica da Empresa Municipal de Serviços Urbanos de Aracaju/SE. Advogada.

E-mail: emiledantascartaxo@outlook.com

2 Possui graduação em Direito pela Universidade Católica de Pelotas (2000), mestrado em Direito pela Universidade de Caxias do Sul (2009) e doutorado em Direito pelo Centro Universitário de Brasília (2017). Advogada e professora adjunta na Universidade Federal de Sergipe e Universidade Tiradentes. Professora do Programa de Pós-graduação em Direito Stricto Sensu da Universidade Tiradentes. Avaliadora do sistema BASis (Portaria 430 de 29 de maio de 2018 MEC/INEP). E-mail: tanisethomasi@gmail.com

3 Graduado pela UNIT (2002), pós-graduado em Direito Civil pela UNIT (2005). Mestre em Direito, na área de concentração constitucionalização em direito, pela UFS (2014). Doutor em direito político e econômico pela Universidade Mackenzie (2018). Professor titular da graduação e do mestrado em direitos humanos do PPGD-UNIT. Professor convidado em cursos de pós-graduação. Avaliador de várias revistas jurídicas. Líder do grupo de pesquisa "Novas tecnologias e o impacto nos Direitos Humanos" do mestrado em direito Humanos da UNIT. Coautor de diversas obras jurídicas e autor dos livros "O Princípio da Função Social da Propriedade Urbana", editora Letras Jurídicas e "Direito e Moradia: uma abordagem crítica", editora Sal da terra, e "Propriedade privada e direito à moradia: uma crítica", publicado pela editora Ideias e Letras, além de autor de diversos artigos jurídicos. E-mail: contato@diogocalasans.com

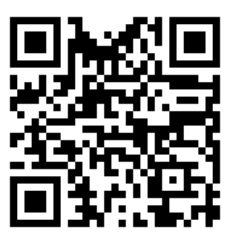

A autenticidade desse artigo pode ser conferida no site https://periodicos. set.edu.br

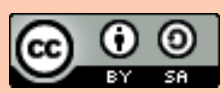

Este artigo é licenciado na modalidade acesso abertosob a Atribuição-Compartilhalgual CC BY-SA

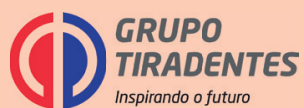

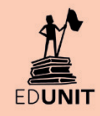

